\title{
A3 3 entre a propriedade e o salário. www.aibr.org MEMÓRIAS DOS TRABALHOS AGRÍCOLAS EM ALPIARÇA (ANOS 50/80)
}

\section{Dulce Freire}

Membro do Instituto de História Contemporânea da Faculdade de Ciências Sociais e Humanas da Universidade Nova de Lisboa e doutoranda na mesma faculdade dulcefreire@fcsh.unl.pt

\begin{abstract}
Resumo
Até aos anos 60 do século XX, Portugal foi um país essencialmente agrícola e rural. O rápido êxodo rural facilitou o abandono ou a transformação da agricultura. Apresenta-se aqui uma reflexão sobre os actuais processos de rememoração das práticas agrícolas numa vila do Ribatejo (Portugal) e sobre a amnésia social verificada relativamente ao passado agrícola, que decorre das transformações ocorridas e dos valores sociais e culturais associados à reconstrução da identidade da vila de Alpiarça.
\end{abstract}

Palavras chave

assalariados rurais, memória social, trabalho agrícola

\begin{abstract}
Until the sixties of the twentieth century, Portugal was dominantly an agricultural and rural country. The rural exodus that took place has originated the abandon and changing of agricultural practices. We present in this text a research concerning the actual processes of remembering agricultural practices from the past and also concerning the observed social memory and its forgotten elements related with the rural past, which is originated by the transformations that took place and the social and cultural values associated with the reconstruction of the identity in Alpiarça, a village of the region of Ribatejo (Portugal).
\end{abstract}

Key words

agricultural work, rural workers, social memory

té aos anos 60 do século XX, Portugal foi um país essencialmente agrícola e rural e, desde então, o processo de desruralização estará apenas consolidado nas maiores cidades. O rápido êxodo rural facilitou o abandono ou a transformação da agricultura. Todavia, a passagem de um sistema agrícola baseado em energia orgânica para outro assente em energia fóssil tem tido diferentes incidências territoriais. Subsistem no país práticas e alfaias agrícolas muito diversas, adaptadas às características dos sistemas agro-ecológicos e sociais em que decorre a agricultura (Brito e Baptista, 1996). 
Tendo presente o que escreveu M. Halbwachs (1994), o cultivo da terra e o desenrolar do quotidiano em comunidades rurais fizeram parte dos quadros sociais em que decorreu a existência de sucessivas gerações e também os primeiros anos de socialização de quantos protagonizaram o êxodo dos anos 60 e 70. É plausível admitir que a maioria da população portuguesa guardará memórias dos trabalhos agrícolas. Quando inquirimos alguém com mais de 50 anos acerca do seu percurso e vivências é muito provável que ainda obtenhamos informações sobre o tema de um testemunho directo. Alguém que durante pelo menos uma parte da vida desempenhou várias tarefas relacionadas com a exploração da terra para a obtenção de colheitas.

Num país onde até há poucas décadas o sector primário perpassou a densidade das relações económicas e sociais, Alpiarça, a comunidade que está no centro da investigação que tenho desenvolvido nos últimos anos, não é excepção. O ponto de partida da pesquisa visava contribuir para o esclarecimento dos processos de modernização da agricultura e de mudança social em Portugal durante a "revolução verde". O que tem implícito conferir grande importância às tecnologias usadas em cada momento e às circunstâncias em que surgem as inovações: adopção ou não de novas tecnologias e culturas, extinção ou adaptação de formas de saber fazer, aquisição ou não de conhecimentos, grupos sociais mais e menos empenhados em inovar, etc (Fernández Prieto, 2003; Rosemberg, 1994). As perspectivas de abordagem destas questões e as metodologias que considerei pertinente adoptar conduziram-me à selecção deste concelho para centrar a investigação. A escolha assentou em quatro critérios principais. Por um lado, aqui a agricultura era não só uma actividade económica hegemónica como estava há muito ligada ao Estado e ao mercado. Por outro, as pesquisas prévias indicaram a existência de arquivos relativos a várias instâncias dos poderes públicos organizados e consultáveis, e, também, foi possível estabelecer contactos que viabilizassem o trabalho de campo. A investigação decorreu assim nas fronteiras de várias disciplinas, sobretudo nas da História e da Antropologia, mas também nas da Geografia, Agronomia e Sociologia.

Entendo que trabalho agrícola - mais rigorosamente trabalhos agrícolas - é uma designação genérica e sintética para a enorme diversidade de conhecimentos, alfaias e tarefas que é necessário congregar para garantir a satisfação das necessidades específicas das diferentes culturas presentes em cada sistema agro-ecológico. Numa economia que, até aos anos 60 , tinha cerca de 50 por cento da população activa no sector primário, os trabalhos agrícolas representavam a esmagadora maioria das ocupações disponíveis (Martins e Monteiro, 2002). Esta designação encerra inúmeras componentes que remetem para os contextos sociais, culturais, económicos e políticos em que decorre a exploração da terra. Em Alpiarça, numa época em que a mão-de-obra era numerosa e vital, interessava-me analisar as componentes técnicas e tecnológicas e também as relacionadas com as relações de classe, os estatutos e as condições laborais dos trabalhadores.

Neste artigo abordo os processos de recolha e os conteúdos de alguns dos materiais reunidos durante a investigação. Na primeira, apresento as estratégias desenvolvidas durante o trabalho de campo para estimular os processos de recordação e tentar ultrapassar o esquecimento que envolvia 
algumas destas componentes. Na segunda, parte evidencio as potencialidades do local onde decorre a entrevista na evocação da memória e na construção dos discursos.

\section{Pesquisa: do campo para os arquivos e vice-versa}

Nas décadas de 50 a 80, grande parte dos habitantes de Alpiarça são migrantes de primeira, segunda e, mais raramente, de terceira geração. Vieram quase sempre das zonas montanhosas a montante atraídos pelas promessas de mais facilidades de acesso ao trabalho e à terra oferecidas pelas férteis planícies aluviais. A maioria dos que aqui residem são descendentes de camponeses e, pelo menos durante uma parte da vida, camponeses. Assim, os conhecimentos específicos necessário à obtenção das diversas colheitas que compunham a policultura destas economias faziam parte da herança imaterial transmitida pela família e/ou pela comunidade de origem. Uma vez fixados na borda d'água, os migrantes vão com frequência traçar como objectivo a aquisição de alguma terra ao mesmo tempo que estão atentos às oportunidades para trazer de renda as melhores parcelas. Muitos dos proprietários e agricultores de Alpiarça começaram por adquirir ou arrendar parcelas na zona alta e menos fértil do concelho (a charneca), procurando ao longo da vida, com maior ou menor sucesso, as oportunidades para explorar o campo (a vasta planície aluvial do Tejo), a terra da sua ambição.

O Ribatejo é com frequência inserido nos campos do Sul, o que pode levar a generalizar a esta região características que são mais frequentes no Alentejo. Se as diferenças agro-ecológicas são facilmente detectáveis, já as de organização social podem estar mais dissimuladas. Refiro apenas uma característica, que tem implicações directas nos objectivos deste artigo. Ao contrário do que vários investigadores têm verificado em outras povoações do Ribatejo (Godinho, 2001) e do Alentejo (Cutileiro, 1976), em Alpiarça são raras as linhagens de famílias de assalariados rurais. Pode ser-se assalariado rural sazonalmente ou durante uma fase da vida, mas esta actividade combina-se com o acesso directo ou indirecto à terra. Grande parte dos habitantes, pode assim ter uma visão global do processo de produção. Conhecem e participam nas diversas fases que compõem os ciclos produtivos das culturas praticadas e estão atentos às vantagens e às desvantagens decorrentes da introdução de inovações tecnológicas disponíveis. Isto não impede que nas construções identitárias de alguns grupos, os elementos característicos do estatuto de trabalhador rural, jornaleiro, assalariado surjam sobrevalorizadas a ponto de ocultarem outros traços (Freire, 2004).

Uma comunidade com estas características económicas e sociais fornecia à partida algumas garantias de que não seria difícil encontrar informantes capazes de contribuir para o esclarecimento das várias questões que orientavam a pesquisa. A concepção deste projecto de dissertação de doutoramento visava esclarecer as problemáticas antes enunciadas a partir da aplicação de metodologias com distintas origens disciplinares. A minha formação universitária no ofício de historiadora, apesar de ter decorrido numa época (finais dos anos 80 e inícios dos 90) em que a defesa da interdisciplinaridade se tornou corriqueira - na História a percepção destas vantagens é 
precoce, por comparação com as outras Ciências Sociais, pois estão no âmago do movimento dos Annales (Burke, 1995) iniciado em finais dos anos 20 -, não contemplou a aquisição de competências em outros métodos de pesquisa que não as relacionadas com a selecção e análise de documentos escritos. Ainda que a prática seja diferente, a utilidade, ou a inevitabilidade, de realizar pesquisas interdisciplinares para estudar as sociedades contemporâneas tem sido evidenciada por inúmeros autores. Neste caso, desejava combinar a consulta de diversos arquivos, a que os historiadores estão habituados, com o trabalho de campo e as recolhas de história oral, indissociáveis da formação dos antropólogos. Em projectos de investigação anteriores em que tinha participado tinham sido testadas algumas das virtuosidades de desenvolver estas metodologias em simultâneo e de forma complementar (Freire, Fonseca e Godinho, 1999). Tratava-se agora de as aplicar a um "estudo de comunidade" para esclarecer questões colocadas a partir da História.

$\mathrm{Na}$ planificação das fases da pesquisa, o trabalho de campo começou cerca de dois anos e meio depois do início desta. Antes, durante e depois do trabalho de campo fiz pesquisa em arquivos de âmbito nacional, regional e local e, ainda, entrevistas a informantes que não sendo de Alpiarça desenvolveram actividades profissionais ou políticas relevantes para a compreensão dos problemas em análise. Os períodos de estadia em Alpiarça visavam principalmente avaliar a adequação das condições agro-ecológicas aos objectivos tecnológicos e produtivos definidos pelos engenheiros oficiais e recolher as perspectivas dos habitantes acerca dos múltiplos aspectos que se aliaram para potenciar ou não a transformação da agricultura.

A documentação guardada nos arquivos administrativos - sejam locais, regionais ou nacionais - dá conta de acontecimentos excepcionais ou de aspectos relevantes para a gestão dos assuntos públicos e políticos, mas é quase sempre omissa acerca dos aspectos banais e rotineiros do quotidiano. Esta documentação, sendo essencial para avaliar os objectivos e a extensão do Estado e do mercado no território, é pouco útil para estudar os trabalhos agrícolas e os impactos das mudanças tecnológicas. É certo que diversos relatórios de técnicos dos serviços oficiais descrevem algumas tarefas, muitas vezes para mostrar quanto estão erradas e como justificação de uma intervenção para as alterar. Alguns estudos locais e regionais, relatos de carácter etnográfico e artigos vários também podem fornecer dados úteis. Contudo, mesmo que a intenção do sujeito seja testemunhar e divulgar informações, o processo cognitivo da escrita implica uma ordenação e síntese das ideias e dos dados que não facilitam a transmissão das particularidades e dos pormenores associados aos diversos trabalhos agrícolas.

Durante o trabalho de campo, os dados foram procurados pela conjugação de três fórmulas: reconhecimento das áreas urbanas e rurais do concelho e dos vizinhos; conversas e entrevistas semi-dirigidas com informantes; utilização de documentos de carácter privado e público fornecidos por informantes ou integrados em arquivos dos órgãos de poder e instituições locais. Cada trabalho de campo é sempre um novo desafio e encerra inúmeros imprevistos e obstáculos. Durante a preparação e a estadia em Alpiarça, os imprevistos não me abandonaram. O acesso às memórias 
dos trabalhos agrícolas exigiram a ultrapassagem de vários obstáculos, alguns não previstos, quer relacionados com o terreno, quer com os mecanismos menmónicos e com o esquecimento.

Os primeiros meses dedicaram-se ao reconhecimento dos territórios urbanos e rurais e ao reatar e fortalecimento dos contactos antes estabelecidos. Os informantes começaram por ser escolhidos pelo sistema da "bola de neve", em que pedia a um entrevistado a indicação de outros potenciais informantes (Burgess, 1997). Contudo, este método revelou-se inadequado para esclarecer as questões colocadas. A "bola de neve" revelar-se eficaz para aceder aos membros de um mesmo colectivo (Godinho, 2001), mas estava a ser difícil chegar a informantes que estando inseridos em outras redes sociais pudessem apresentar distintas perspectivas sobre as questões. Verificava que se havia um conjunto de informações que eram dadas havia outras que eram sistematicamente esquecidas ou minimizadas. Constatei, por exemplo, que se as fontes escritas tendem a apresentar versões fixadas das técnicas e do desenrolar das tarefas - negligenciando as mudanças ou as alianças entre estas e as continuidades, alargando sem critério os âmbitos temporais e espaciais de observações particulares -, algo de semelhante se estava a passar com o conteúdo das entrevistas.

Num concelho com mais de nove mil habitantes, em que a maior parte vive na vila que tem um povoamento urbano disperso e outras centenas em povoações mais pequenas, tornava-se difícil ter acesso aos espaços de sociabilidade alargada e ainda mais aos espaços domésticos. Procurei então contactar directamente com os agricultores e trabalhadores quando estes estavam a desenvolver actividades nas terras. Esta estratégia permitir-me-ia aceder apenas àqueles que ainda partiam regularmente para as parcelas, mas deixava de fora a larga maioria que participou nas actividades agrícolas durante o período cronológico da minha análise. Todavia, esta era uma tentativa para encontrar informantes com diferentes posições nas redes sociais e com distintos conhecimentos acerca dos assuntos que me interessavam. Também esperava pela "abertura de portas" para pôr em marcha "bolas de neve" que me levassem a outros informantes. Nomeadamente, aos que repartiam os dias entre pequenas tarefas agrícolas ou oficinais e os locais de sociabilidade masculina em vários pontos da vila. A aplicação desta estratégia apenas se tornou possível quando as condições meteorológicas permitiram retomar com regularidade as actividades agrícolas. O desenrolar do trabalho de campo foi influenciado por um Inverno frio e chuvoso (provocou inundações na lezíria, afectando a zona baixa do concelho) que não aconselhava os potenciais informantes a actividades ao ar livre e que como tal reduzia as minhas possibilidades de os contactar.

A chuva abrandou a partir de Abril de 2003. Desde essa altura, o meu quotidiano desenrolava-se com frequência entre os arquivos (nesta fase privilegiei os localizados na sede de distrito, a 12 quilómetros) e as conversas informais com os agricultores e os trabalhadores que aleatoriamente encontrava a explorar parcelas de terra na lezíria ou na charneca. Foi possível conciliar estas duas modalidades de pesquisa porque percebi que a melhor altura para contactar os potenciais informantes era quando estes estavam quase a terminar ou já tinham terminado as suas tarefas. Se fosse mais cedo estariam demasiado preocupados com o que tinham para fazer e corria o risco de 
nem os vislumbrar na imensidão das propriedades. Com o avançar da Primavera, o fim de tarde tornava-se mais agradável para conversar. Durante algumas semanas consegui assim conciliar as duas metodologias, porque o encerramento dos arquivos coincidia com o início do período mais adequado ao trabalho de campo.

No princípio, não conhecia as pessoas que interpelava nem elas me conheciam. Nos primeiros contactos explicava os objectivos do meu trabalho, fazia algumas perguntas e, às vezes, tirava fotografias ao informante e às actividades que estava a executar. Em alguns casos estes encontros repetiram-se, em outros foi possível conduzi-los para locais de sociabilidade alargada (locais de lazer ou de trabalho, como o mercado de melão e a adega cooperativa) ou para o espaço doméstico (nomeadamente para entregar as fotografias), em outros não voltei a encontrar o informante. Quando foi possível, fiz entrevistas a um ou mais elementos do agregado familiar e também consegui pôr em marcha a "bola de neve". O elevado grau de incerteza desta estratégia foi frequentemente compensada pela disponibilidade e afabilidade dos informantes e, principalmente, como especificarei no ponto seguinte, pelo poder do contexto na evocação da memória.

Contudo, chegar deste modo aos potenciais informantes exigia ainda ultrapassar mais obstáculos, literalmente, de terreno. A extensão da área a percorrer, mesmo sem a combinação com a pesquisa arquivística na cidade de Santarém, aconselhava a utilização de automóvel. Este era um dos instrumentos de trabalho com que contava desde o princípio, mas estacionar era um grande problema. Todas as estradas são estreitas, algumas com muito trânsito outras de terra batia ou em mau estado. As bermas quase nunca existem. Na estrada que liga a vila à sede de distrito, em 7 quilómetros há dois sítios públicos para estacionar e de ambos os lados da faixa de rodagem existem valetas fundas para escoamento de águas da chuva. Para estacionar tinha de escolher os locais públicos ou a propriedade privada, o que poderia constituir o levantamento de novos obstáculos ao sucesso do trabalho de campo. A maior parte das vezes, estacionei em propriedade privada, mas só quando estavam pessoas nessa propriedade a quem poderia explicar os propósitos da invasão.

A configuração da propriedade e as características da agricultura moderna também não facilitaram a pesquisa. As parcelas, mesmo encabeçando com as estradas e não sendo muito largas, são sempre muito compridas (podem ter mais de mil metros de extensão), o que não permite vislumbrar com facilidade se anda alguém a trabalhar e torna difícil percorrê-las a pé. Para mais, a maior parte das tarefas da agricultura industrial requer pouca mão-de-obra (algumas, como a rega com pivot, depois de activadas desenrolam-se sozinhas) e, quando se está a trabalhar, o ritmo é imposto pelas máquinas (rápidas, barulhentas e sempre em acção), o que não propícia a conversa. Na parte final do ciclo vegetativo, algumas culturas (milho, vinha, pomares) também não a facilitam. Tornam-se tão altas e densas que é difícil descobrir os interlocutores e acompanhá-los com o olhar.

As informações assim obtidas juntaram-se às recolhidas em outros contextos. Estabeleci contactos com informantes num dos centros de dia para idosos existente na vila, em associações locais, em 
cafés e mercearias, em casas particulares, na via pública, em oficinas, em mercados. Os assuntos visados nas entrevistas informais e semi-dirigidas que realizei não se restringiam aos trabalhos agrícolas. Interessavam-me múltiplos aspectos relacionados com percursos individuais e familiares, quotidiano, actividades políticas e associativas, relações com os vários organismos do Estado, possibilidades de produzir e comercializar, extensão das redes sociais para fora do âmbito local, etc.

Comprovei, mais uma vez, que o recurso à história oral proporciona o acesso a perspectivas e discursos que, apesar de serem vitais para a compreensão de diversas questões, ficariam excluídos da História (Marinas e Santamarina, 1993; Perks e Thomson, 2000). A combinação do trabalho de campo com o trabalho de arquivo, mais do que permitir superar lacunas nos dados fornecidos por uma ou outra fonte, ampliou o alcance e a profundidade dos esclarecimentos obtidos acerca das vivências dos membros desta comunidade. Algumas das potencialidades da utilização em simultâneo destas metodologias podem ser aferidas pela diversidade dos documentos que recolhi (correspondência pública e privada, artigos de imprensa, livros, cardeno de campo, fotografias, mapas, entrevistas gravadas em cassetes áudio) outras enriqueceram e estarão dissimuladas no saber intuitivo proporcionado pelo trabalho de campo.

\section{Memórias dos trabalhos e das "lutas"}

No Ribatejo existe a maior extensão de terras férteis de que o país dispõe e os ribatejanos gostam de comparar as planícies aluviais do Tejo com as do Nilo. Consideram-se progressistas, não só em termos políticos - referindo-se aos apoios prestados às causas liberais durante o século XIX, republicanas e democráticas no século XX -, como em questões tecnológicas - na segunda metade do século XIX, terá sido aqui experimentada a primerira ceifera debulhadora introduzida no país e houve grande adesão às novas técnicas exigidas pela viticultura pós-filoxera.

Nas interpretações locais, Alpiarça espelha e, às vezes, amplia estas características regionais. No concelho, como na região, a vinha e o vinho dominam a economia. E outras culturas modernas (sobretudo, arroz e melão), também foram conquistando algum peso na economia local. Muitos proprietários e agricultores especializaram-se nestas produções e deixaram de cultivar todos os bens necessários ao abastecimento doméstico. Os rendimentos obtidos pela capacidade de satisfazer as apetências dos mercados urbanos nacionais e internacionais potenciaram a mobilidade social dentro da comunidade. Depois da II Guerra Mundial, os agricultores e proprietários do concelho, tal como muitos congéneres da região, estiveram entre os que revelaram melhores capacidades para introduzir as mudanças decorrentes da passagem de uma agricultura assente em energia orgânica para outra dependente de energia fóssil. As transformações directa e indirectamente induzidas por esta passagem marcaram o quotidiano e os percursos de grande parte dos alpiarcenses.

Apesar de tudo, as formas de exploração da terra são muito semelhantes às usadas nos concelhos vizinhos. Apenas, no caso do melão, têm sido nos últimos anos evidenciadas as particularidades 
locais. Quanto às actividades políticas é diferente. A identidade local tem sido alicerçada na excepcionalidade da defesa dos valores democráticos revelada ao longo de várias gerações. Entre a I República (1910-1926) e o regime democrático (instaurado em 1974) muitos dos habitantes estiveram envolvidos em actos de resistência e conflito contra o poder central. Durante o Estado Novo, esta era uma das povoações permanentemente assinaladas pelas autoridades com o ponto vermelho da subversão. Nas faixas etárias dos meus entrevistados (entre os 50 e os 70 anos) são muito frequentes os testemunhos directos dos que participaram (muitas vezes como simpatizantes ou militantes do Partido Comunista Português) na organização e no desenrolar das lutas depois da II Guerra Mundial.

Durante os primeiros meses de estadia em Alpiarça, constatei que as componentes dos trabalhos agrícolas que permaneciam na memória social eram as que remetiam para os movimentos sociais ocorridos antes de 25 de Abril de 1974. Os relatos dos meus informantes detinham-se com frequência na descrição das lutas da praça de jorna para a obtenção de aumentos de salariais, das greves previstas ou concretizadas para comemorar o 1 de Maio, da reacção dos diversos patrões às reivindicações dos trabalhadores, das degradantes condições em que eram obrigados a trabalhar, das consequências das periódicas crises de desemprego, das precariedades quotidianas, das investidas das polícias que se instalaram no concelho para reprimir e manter a "ordem pública", das dezenas de pessoas que foram presas ou violentadas, etc. Por vezes, os discursos organizavam-se cronologicamente a partir da experiência individual ou colectiva, que poderia remontar às primeiras décadas do século XIX. Outras vezes, descreviam-se com inúmeros pormenores alguns dos acontecimentos mais marcantes e como os ciclos das lutas se inscreviam e dissimulavam no quotidiano. As sequências culminavam quase sempre na Revolução de 1974. E obter dados para os anos que se seguiram não era fácil.

Mas a minha pesquisa exigia que procurasse também recolher as memórias do saber fazer das diversas tarefas exigidas pelas actividades agrícolas e de como estas foram ou não mudando ao longo dos anos, com os incentivos do mercado e do Estado para a modernização. Foi a amnésia social sobre estes aspectos das actividades agrícolas que me levaram a procurar informantes entre os indivíduos que andavam a trabalhar nas explorações agrícolas. Nos meus contactos com estes agricultores e trabalhadores, a propósito das tarefas que estavam a realizar ou da parcela que estavam a explorar pedia-Ihes para me falarem das mudanças que Ihes eram perceptíveis entre o "d'antes" e o "agora". A partir da comparação entre as alfaias e as culturas usadas no passado e na actualidade, da justificação da adopção de umas soluções e não de outras, na evocação do percurso pessoal e familiar, no esclarecimento das minhas dúvidas, foi possível obter informações mais pormenorizadas e diversificadas.

Sobretudo quando entrevistava o mesmo informante em diversos sítios, verifiquei que nos locais que evocavam directamente as actividades agrícolas, os discursos deslizavam de um assunto para outro do sucesso de uma campanha para a destruição provocada por uma grande inundação, dos preços 
do vinho para o valor do hectare, do sabor de uma variedade de melão para as pragas que atacam as oliveiras, da distribuição de uma herança para a atitude de um patrão, das vantagens de um tractor aos tratamentos fitossanitários, etc, - mas mantinham uma coerência que raramente os afastava da terra e dos trabalhos agrícolas necessários à exploração desta. Ainda que se mantivessem referências a acontecimentos e datas precisas, perdera-se a sequência cronológica e muitas observações reportavam-se ao período pós-25 de Abril. Sendo o pensamento e a memória competências que se tornam possíveis pelas interacções sociais e culturais (Halbwachs, 1994), aquelas parcelas e actividades configuram-se como lugares de memória que pontenciam a recordação e permitem a reconstrução dos discursos sobre o passado.

Estas entrevistas proporcionaram-me imensas informações que nunca obteria de outras forma. Permitiram, por exemplo, conferir e esclarecer os dados geográficos e agro-ecológicos constantes da cartografia, de relatórios e de outros documentos escritos. Em muitos casos permanecia na memória dos meus informantes o historial de parcelamento ou emparcelamento de uma propriedade, de tumultuosas ou pacíficas mudanças de proprietário, de culturas dominantes ou extintas, de acontecimentos excepcionais. A conjugação de informações, obtidas em fontes orais e escritas, com o reconhecimento do território do concelho tornou possível delimitar os diversos ecossistemas em que se praticava a agricultura (alguns dos quais, entretanto, abandonados), identificar as características das linhas de água, a verificação do traçado de estradas e caminhos, a configuração dos espaços urbanos, a variação da estrutura da propriedade. O estabelecimento destas conexões tornou-se fundamental para aceder à compreensão dos mecanismos de inscrição das vivências individuais nas da comunidade. Facilitando a percepção de como as relações sociais estabelecidas dentro desta e com o exterior contribuíram ou não para transformar a agricultura de acordo com o modelo hegemónico defendido na época.

\section{Recordar, para quê?}

A amnésia acerca das componentes técnicas, tecnológicas e agro-ecológicas associadas aos trabalhos agrícolas revelada por alguns informantes pode, certamente, atribuir-se à conjugação de inúmeros factores. Alguns decorrerão das características das próprias actividades agrícolas e das transformações ocorridas. Outros estarão associados aos valores e às condições de construção e reconstrução das identidades locais.

Os processos de rememoração destas vertentes dos trabalhos agrícolas exigem que se dê relevância a algo banal, repleto de pormenores e em grande parte inútil. Pouco daquilo que os meus informantes receberam como herança imaterial ou foram adquirindo ao longo da vida é aplicável na agricultura industrial actualmente dominante no concelho. Lembram-se algumas das características gerais, dos traços largos, mas perderam-se os pormenores que não estão associadas aos afectos e à excepção. Por exemplo, os meus informantes mostraram dificuldades em descrever algumas técnicas de cultivo da vinha ou do melão nos períodos mais recuados de que tinham experiência. Esses conhecimentos, 
complexos e minuciosos, tornavam-se quase intuitivos e só se desvendam quando necessários: sabe-se, mas só se sabe até que ponto quando se usa. Cada tarefa requeria uma diversidade de gestos e utensílios que foram sendo abandonados e esquecidos à medida que puderam ser substituídos por outros mais vantajosos. Ao entrevistá-los nas parcelas que exploram há dezenas de anos, ou em outras semelhantes, tornou-se possível recuperar e verbalizar as memórias de saberes e práticas que as mudanças, entretanto, ocorridas tornaram remotos.

Além de individualmente pouco valorizados, estes saberes e práticas também não têm sido relevantes para a construção da identidade da comunidade. Não comprovam as particularidades locais relativamente aos concelhos vizinhos e remetem para os estatutos de agricultor e proprietário. Aqui têm sido valorizados os elementos identitários dos assalariados rurais. Mesmo quando, os rendimentos da exploração da terra se tornaram mais importantes do que os obtidos pela jorna ou quando tiveram ocupações em outros sectores, alguns informantes continuaram a dizer-se jornaleiros. Mais, ainda estas componentes dos trabalhos agrícolas, não se coadunam com os ideais progressistas: estes seriam uma das provas de que, como diziam agrónomos e políticos, a agricultura portuguesa era retrógada. Abandoná-los, ou pelo menos ignorá-los, seria um sinal de progresso.

Os órgãos de poder têm estado indelevelmente ligados à construção e consolidação de identidades projectadas como hegemónicas. Em Alpiarça isso parece também acontecer. Depois de, nos anos que se seguiram ao 25 de Abril, se ter dado grande relevância aos mecanismos de transmissão da memória de oposição ao Estado Novo (comemorações várias, livros, cartazes), nos últimos tempos a autarquia tem vindo a promover eventos e imagens que remetem para os produtos agrícolas e características ecológicas locais . Esta é, aliás, uma tendência que se verifica em outras localidades, o que feito multiplicar pelo país feiras e festividades de inspiração agrícola e/ou gastronómica.

Os alicerces desta patrimonialização de alguns produtos agrícolas e de algumas paisagens rurais estão ainda em construção. Uma das questões que será interessante acompanhar prende-se com lugar que estes vão ocupar na memória colectiva e com os conteúdos que serão valorizados nos discursos e nas imagens transmitidas. Modificar e destruir está implícito na recordação, já que apenas conseguimos reconstruir uma parte do que vivemos ou do que ouvimos, mas neste como em outros casos, aos cientistas sociais cabe questionar como e porquê estes processos ocorrem. A par dos mecanismos da memória deverão também ser estudadas as condições sociais do esquecimento.

\section{Bibliografia}

Brito, J. e Baptista, F. Coords. (1996). O voo do arado. Lisboa: Museu Nacional de Etnologia.

Burgess, R. (1997). A pesquisa de terreno. Uma introdução. Oeiras: Celta Editora.

Burke, P. (1995). Una rivoluzione storiografica. Roma: Editorial Laterza. 
Cutileiro, J. (1977). Ricos e pobres no Alentejo. Uma sociedade rural portuguesa. Lisboa: Sá da Costa.

Fernández Prieto, L. (2003). El papel del Estado español en la innovación tecnológica de la agricultura en el siglo $X X$. Dactiliografado. Santiago de Compostela: Universidade de Santiago de Compostela.

Freire, D., Fonseca, I., Godinho, P. (1999). Resistência e agitação no contexto rural português (1926-1974). Relatório de Investigação/Dactilografado. Lisboa: FCSH/FCT.

Freire, D. (2004). Identidades e solidariedades. Assalariados rurais e pequenos agricultores no Sul de Portugal (anos 50-70). Em VII Congreso de la Asociación de Historia Contemporánea. Santiago de Compostela: Universidade de Santiago de Compostela [pré-actas em CDRom].

Godinho, P. (2001). Memórias da resistência rural no Sul. Couço (1958-1962). Oeiras: Celta Editora.

Halbawchs, M. (1994). Les cadres sociaux de la mémoire. Paris: Albin Michel.

Marinas, J.M. e Santamarina, C. (1993). La historia oral: métodos y experiencias. Madrid: Debate.

Martins, C. A. e Monteiro, N.G., (2002). A agricultura: dicionário. Em História do trabalho e das ocupações (vol.III). L.N. Madureira, Coord. Oeiras: Celta Editora.

Nora, P. (1986). Entre mémoire et Histoire. Em Les lieux de mémoire: la République. P. Nora, Org. Paris: Gallimard.

Nora, P. (1998). La aventura de les lieux de mémoire. Em Memoria y Historia. J.Cuesta Bustillo, Ed. Ayer ( $\left.n^{\circ} 32\right)$.

Perks, R. e Thomson, A. (2000). The Oral History Reader. London: Routledge.

Rrosemberg, N. (1994). Exploring the Black Box. Technology, Economics and History. Cambridge: Cambridge University Press. 